\section{CAREERS IN ZOOLOGY}

" CAREERS in Zoology-Possibilities and Train1 ing" was the subject of a discussion at the annual meeting of the Association of British Zoologists held in London on January 11. The Council had proposed this topic in an endeavour to provide those responsible for the teaching of zoology in schools, universities and kindred institutions with some guidance on openings likely to be available for young zoologists in the future and what, if any, special directions training should take.

Early in the discussion it became apparent that the field of employment in zoology is clearly divided into two parts: (i) teaching coupled with academic research, and (ii) applied work with research that is, to some extent at least, $a d$ hoc and directed. All speakers who alluded to this division expressed their dissatisfaction with its existence, and stated that they believed that for the general health of zoology it is imperative to break down the division as soon as possible. Prof. J. Gray (Cambridge), opening the discussion, emphasized the desirability of encouraging first-class students to enter the applied field, where interesting but difficult problems await solution; increased facilities for fundamental research and a feeling of intellectual freedom are at least as important as high salaries. At present there is little relation between the supply and the demand for recruits; the numbers involved are often small, and no one could afford to undergo specialist training in such subjects as helminthology and protozoology unless assured of a reasonable career. Prof. Gray felt that many existing difficulties would be overcome if there were closer liaison between university teaching departments and institutions undertaking applied studies; he felt that much could be said for extending the principle whereby individuals should occupy simultaneously a university post and an official position under such organisations as the Medical or Agricultural Research Councils.

Dr. F. P. Coyne (Imperial Chemical Industries, Ltd.) suggested that what industry and commerce require of the entrant into the field of applied zoology is not that he be a ready-made specialist, but that he have a capacity for clear thinking. The idea that he need have an encyclopædic knowledge of a special field, or of the whole of zoology for that matter, is found among non-applied zoologists but not among those already in the applied field. Beyond a general training in zoology, the best additional qualification for applied work is probably a degree or diploma in agriculture. An acquaintance with statistical methods is also desirable, first so that the output of statistical departments can be appreciated, and secondly that experiments can be planned from the beginning in a form that will give results that statisticians can readily deal with. This does not, of course, mean that the zoologist should attempt to become a fully developed mathematician.

Prof. C. H. Waddington (Edinburgh) began his observations by pointing out that while Britain had, at one time, led the field in genetics, the subject has latterly fallen behind somewhat, and the maindevelopments have been taking place elsewhere. Genetics cannot be purely a study of breeding experiments, but successful research is dependent on parallel advances of knowledge in the physiology of plants and animals, and in the analysis of exactly what factors contribute toward the qualities of plant or animal that it is desirable to improve. He illustrated this by pointing out some of the many factors that contribute toward a satisfactory milk-yield in dairy cows. Another field in which advances are due to be made is that of genetics in relation to general evolutionary processes. Prof. Waddington suggested that genetics should be more integrated into the general subject of analytical biology, and the past tendency towards the separation of genetics from zoology should, if possible, be reversed. Future laboratories of genetics will require zoologists as well as specifically trained geneticists.

Speaking of fisheries research and work on marine biology generally, Mr. Michael Graham (Fisheries Laboratory, Lowestoft) pointed out that while proposed developments may lead to an average intake of some two or three individuals every year, this could not be expected to be a regular intake owing to inevitable inequalities in age-groups em. ployed. He therefore suggested that while an individual student might well train for fisheries or other marine research, if aptitude had been shown, he would be well advised to have a good alternative subject, with which to seek employment should openings in fisheries and related work prove to be few and far between. Mr. Graham pointed out that it is now possible to gain some information about the financial side of careers in zoology by reference to the White Paper on the Scientific Civil Service, since the conditions laid down therein apply to work undertaken or supported by Government institutions, and would certainly be used as a guide by the majority of research stations.

An interesting account of developments in the relatively small field of research on the anti-fouling of ships was given by Prof. J. E. Harris (Bristol). He pointed out that while this work will be almost certain to continue, it cannot be expected to absorb a large number of zoologists. Prof. Harris emphasized that this applied work brings the research worker into contact with fundamental problems of marine biology; and that those who control financial aspects are becoming convinced that the division between the applied field and the non-applied is, perhaps, much less apparent in this field than elsewhere.

Dr. E. L. Taylor (Veterinary Laboratories, Weybridge), discussing veterinary science generally and helminthology in particular, pointed out that work in these fields tends perhaps to overlap into other fields to a greater extent than any other type of work in which zoologists normally find employment. However, it would not be desirable to add pharmacology, for example, to the zoologist's equipment; but perhaps the general subject of parasitism in all its manifestations, and including immunity, might receive more attention in the general training of zoologists. Dr. Taylor stressed the fact that the fundamental approach to the problems of parasitic diseases is ecological, since all these diseases are, on final analysis, the result of man-made derangements of environment. Losses due to parasitic disease are enormous, and it is to be hoped that, in future, zoologists, even if in limited numbers, may find employment in this field.

The field of employment before the young entomologist was analysed by Dr. V. B. Wigglesworth (Cambridge). It consists - with exceptions, of courseof a limited number of openings in teaching, which is in fact part of pure zoology; a limited number in systematic entomology or museum work; and a 
much larger number in applied work. An applied entomologist is primarily an investigator, and he is not fully trained until he is acquainted with the industry which he serves. University training should therefore aim at a synthesis of insect morphology, physiology and taxonomy, and afterwards a year or two of research. In addition, the applied entomologist will require at some stage a training or a period of apprenticeship in the industry which he is to serve. Dr. Wigglesworth concluded by enumerating some of the very diverse organisations wherein entomologists can seek employment if prepared to carry out applied work.

In the general discussion among members which followed the introductory papers, a number of points were made. It was suggested that biology, and therefore zoology, is now such a complex subject, with roots deep down in chemistry, physics and mathematics, that certain preliminary training in these subjects should be insisted upon before work in zoology itself is commenced at any other than a most elementary level. Such training is required for medicine; why should zoology exempt its trainees from being of a certain educational standard in such very relevant subjects? The great need for systematic zoologists was mentioned, but the opinion was expressed that systematists gradually develop in the course of general zoological training, and few, if any, could be specifically trained for taxonomic work. In any event, systematics is a very specialized field, and a relatively small one compared with the rest of the general field of zoology.

One speaker suggested that the rising cost of living, along with the relatively poorer career prospects in biology, is leading to an ever larger number of potential zoologists taking up medicine rather than zoology; but this point of view was immediately controverted by another speaker.

The fact that zoologists appear to have succeeded in a great number of non-zoological war jobs was cited as showing that zoology as a discipline has very considerable educative value, as distinct from being a subject of training in a specific technical field, and that it is desirable that this should be stressed. 'To speak of 'training' in zoology implies in itself that the trainee is to become a professional zoologist. No one would talk of a 'training' in classics, but an 'education' in classics was held to fit a man for almost any job where administration is involved. Is there anything that makes the man 'educated' in the classics or such similar subjects automatically a better potential worker than the man 'trained' in zoology ?

JoHN Smart

\section{MODERN METHODS OF FIBRE INVESTIGATION} TUDIES on the properties of single fibres have
been particularly successful in increasing our
knowledge of the structure of natural and synthetic
high polymers and of the basic principles underlying
many industrial processes. Special techniques have
been developed to overcome the experimental
difficulties involved in making measurements on
single fibres, and many of these methods were dis-
cussed at a Conference on Single Fibre Testing held
by the Textile Institute in the University of Leeds on January 29. The February issue of the Journal of the Textile Institute, in which the papers read at the Conference are published, forms a valuable addition to scientific literature, and will be a useful practical reference volume for all who are interested in this field of investigation.

Determinations of breaking load, extension at break, and other elastic properties which have attracted many workers were discussed by R. Meredith, and an instrument designed by J. Sikorski, C. S. Whewell, and H. J. Woods was described in detail on account of its having proved satisfactory for making such measurements over a period of ten years. Interest in studies on bending has recently been intensified, and measurements of bending modulus may be made simply by the use of apparatus described by P. Carlene and by L. G. Wilson. R. H. K. Thomson and D. Traill gave an account of an apparatus designed to assess the resistance of fibres to repetitive bending - a property which is equally important, although some doubt was expressed as to the correlation between results obtained by this method and those obtained on material in bulk. Deformation of fibres by shearing stresses was considered by A. Finlayson, and papers by $R$. Meridith and by W. E. Morton and F. Permanyer supply details of satisfactory methods for measuring torsional rigidity and torsional relaxation, which are particularly significant in relation to the spinning of textile fibres. Determination of axial swelling by direct microscopic observation is slow and difficult, especially with fibres of varying and irregular crosssections, but new methods of measurement devised by J. M. Preston and S. Das Gupta and by F. L. Warburton are much simpler.

Other fibre properties, less frequently studied, were the subjects of a contribution by J. M. Preston on the refractive index of textile fibres, and an interesting account of preliminary experiments by G. E. Collins on the surface tension method for measuring the perimeter of a fibre and the contact angle.

Weighing the single fibre is a necessary operation in most investigations, and has in the past been done by using torsion balances. These instruments are delicate and often lack stability, but the cantilever microbalance of $\mathrm{E}$. Lord is more robust and stable, and is very suitable for routine work.

Sampling is one of the most important aspects of single fibre testing, and statistical analysis of the results is in most cases necessary. These topics were discussed by R. C. Palmer and H. E. Daniels, who illustrated their contribution by reference to the measurement of fibre length. The value of modern single fibre testing is possibly best illustrated by the results which have been obtained on animal fibres, for although opinions may differ on the detailed interpretation of certain observations, studies on the properties of natural and chemically modified animal fibres under various conditions have been particularly successful. Some of this work was described by J. B. Speakman, who gave a lucid account of the uses of load/extension curves, set, and supercontraction in the routine control of wool textile processes as well as in research on the chemistry of animal fibres. The new techniques developed by R. D. Preston and by F. Happey and A. W. Porter for obtaining $\mathrm{X}$-radiograms of single fibres should also prove valuable in investigations on the structure of fibres. C. S. WHEWELI 